\title{
Galhas e deformações em Jambu (Spilanthes oleraceae) causadas por Tecaphora spilanthes (Ustilaginales)
}

\author{
Leila Nakati Coutinho ${ }^{1}$, Christiane Ceriani Aparecido ${ }^{1}$, Mario Barreto Figueiredo ${ }^{1,2}$
}

\author{
${ }^{1}$ Centro de Pesquisa e Desenvolvimento de Sanidade Vegetal - Instituto Biológico "Dr.Arthur Neiva" - Av. Cons. Rodrigues Alves, 1252 - CEP \\ 04014-002 - Vila Mariana - São Paulo - SP, e-mail: coutinho@ biologico.sp.gov.br \\ ${ }^{2}$ Bolsista do CNPq - Produtividade em Pesquisa \\ Autor para correspondência: Leila Nakati Coutinho \\ Data de chegada: 17/05/2005. Aceito para publicação em: 22/12/2005.
}

\section{ABSTRACT}

Coutinho, L.N.; Aparecido, C.C.; Figueiredo, M.B. Galls and deformation on jambu (Spilanthes oleraceae) caused by Tecaphora spilanthes (Ustilaginales). Summa Phytopathologica. v.32, n.3, p.283-285, 2006.

The herbaceous Asteraceae known by the name jambu and other common names is native to the Amazon region has been used and cultivated for culinary, medicinal, insecticidal and ornamental purposes. It is also used as spice for local food in Belém city, Pará State. The medicinal value of this plant has been known and

Addition keywords: medicinal plant, smut, first report it has been studied in cultivated plants in Botucatu county, São Paulo State. This is the first report of a smut (Tecaphora spilanthes Freire \& Vànky) affetcting this plant in the São Paulo State. The smut causes losses and also reduced the quality of the plants.

\section{RESUMO}

Coutinho, L.N.; Aparecido, C.C.; Figueiredo, M.B. Galhas e deformações em jambú (Spilanthes oleraceae) causadas por Tecaphora spilanthes (Ustilaginales). Summa Phytopathologica. v.32, n.3, p.283-285, 2006.

A planta herbácea jambú, pertencente à família Asteracea, conhecida por diferentes nomes populares, como agrião do Pará, erva maluca, botão de ouro, etc., é uma espécie nativa da Amazônia, bastante utilizada na culinária regional e, também, apresenta importância medicinal e inseticida tendo sido, por este motivo, introduzida em Botucatu, SP. Nesta Nota é relatada a primeira constatação do carvão Tecaphora spilanthes Freire \& Vànky no Estado de São Paulo. A infecção pode causar severas perdas e reduzir a qualidade das plantas.

Palavras-chave adicionais: planta medicinal, carvão, etiologia

O jambú (Spilantes oleraceae L.) planta herbácea pertencente à Família Asteraceae é amplamente cultivada em vários municípios da região nordeste do Estado do Pará, nos quais o seu consumo é significativo em festas populares. Trata-se também de um produto importante na culinária regional, na alimentação cotidiana e na medicina popular. O jambú é conhecido, no Pará, por vários nomes populares como: agrião do Pará, agrião do Brasil, agrião do Norte, jabuaçú, erva maluca, jaburama, botão de ouro, etc. Poltronieri et al. (5) relatam diversas informações sobre o jambú.

Em seu uso fitoterápico tradicional as folhas e as flores do jambú são utilizadas no preparo de infusões para o tratamento da dispepsia, malária, infecções da boca e da garganta $(1,4,6)$. É, também, recomendado contra a avitaminose $\mathrm{C}$ e como antibiótico e anestésico. Nas folhas mais tenras é produzido um óleo essencial com índice elevado de uma substância conhecida como spilanthol responsável por tais propriedades.

Em decorrência de seu potencial terapêutico, o jambú tem, atualmente, desperatdo o interesse de pesquisadores ligados à área da saúde. Essa é, provavelmente, a razão pela qual esta planta está sendo cultivada em Botucatu, SP, pela empresa ANIDRO do Brasil Ltda.

Em Março de 2005, o Centro de Pesquisa e Desenvolvimento de Sanidade Vegetal do Instituto Biológico "Dr.Arthur Neiva", recebeu material para exame, determinação e identificação de um patógeno que estava causando um grande número de deformações e galhas no colo da planta e, também, nas hastes principais e secundárias (Figura $1-\mathrm{A}, \mathrm{B}, \mathrm{C}$ ). Essas galhas lembravam aquelas causadas por certas bactérias e, provavelmente, ocorrem por hiperplasia e hipertrofia das células do hospedeiro como resposta ao parasitismo do fungo (3). As galhas mais jovens apresentavam coloração verde-clara, superfície saliente e lisa. Em fase mais adiantada da infecção foram observadas galhas rompidas, com exposição dos soros e esporos. No interior destas galhas estão abrigados os soros, semelhantes à pequenos alvéolos e, dentro dos quais são produzidos esporos em grande número. Esses esporos pluricelulares apresentam-se firmemente unidos, originando as "bolas de esporos" ou "spore balls" (Figura 1-D, E, F). Estudos mais detalhados, realizados com auxílio da microscopia 


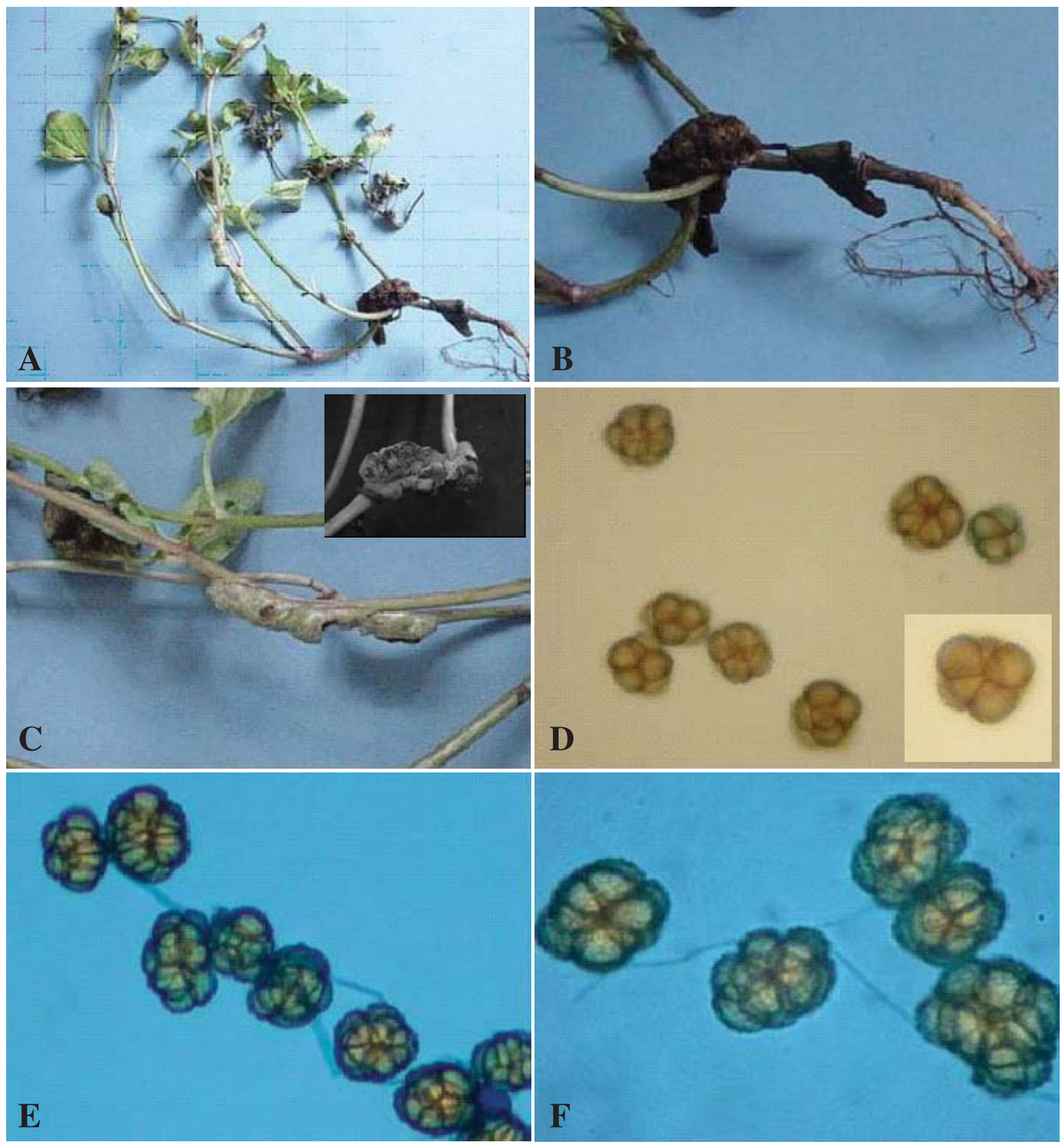

Figura 1 - Tecaphora spilanthes (Ustilaginales) sobre jambú (Spilanthes oleraceae L.). A $\rightarrow$ Vista geral da planta com sintomas. B $\rightarrow$ Galha na região do colo. $\mathrm{C} \rightarrow$ Galha na haste. $\mathrm{D}, \mathrm{E}, \mathrm{F} \rightarrow$ Esporos.

$\mathrm{E} \rightarrow$ Esporos ("spore balls") se desenvolvendo em sequiência sobre o micélio dicariótico.

$\mathrm{F} \rightarrow$ Ornamentação externa (superfície verrugosa) dos esporos ("spore balls"). 
estereoscópica e óptica e, também, de consulta à literatura especializada, permitiram a identificação de um fungo do gênero Tecaphora, um carvão (Ustilaginales) causador de uma doença sistêmica.

O gênero Tecaphora descrito por Finguerhult em 1836, conta com cerca de 30 espécies conhecidas, que parasitam membros de várias famílias botânicas $(2,7)$. As espécies de Tecaphora que ocorrem sobre a família Asteraceae (Compositae) são conhecidas apenas sobre a sub família Asteroideae $(2,8)$

Consultando a literatura pertinente pudemos constatar que se tratava de Tecaphora spilantes, espécie coletada por Freire, em Belém do Pará e descrita por Freire e Vànky $(2,3)$.

No ano de 1986, Freire (3) estudando esta doença, descreveu os sintomas, sinais, germinação das "bolas de esporos", chegando a identificar o gênero Tecaphora, supondo tratar-se de espécie nova. Mas, não sendo especialista em carvões (Ustilaginales) e não contando com um herbário para possíveis comparações com outras espécies do mesmo gênero, preferiu encaminhar amostras para um dos poucos especialistas hoje existentes nesse grupo de fungos o Dr. Kàlman Vànky na universidade de Tünbiguen na Alemanha.

\section{Descrição do fungo}

Tecaphora spilantes Freire \& K. Vànky. Mycotaxon 59: 97, 1996 Soros com galhas policísticas sobre o colo, haste principal e secundárias, pecíolos folhas, mais raramente sobre o talo florífero. Soros com 1-2 mm. de diâmetro até $6 \mathrm{~cm}$ de comprimento e, por coalescência de soros contínuos (galhas), freqüentemente com 2-3 cm de largura. Inicialmente verdes depois marrons, com superfície irregular. Freqüentemente causando pronunciadas distorções e deformações das partes afetadas da planta hospedeira.

$\mathrm{Na}$ maturidade, os tecidos do hospedeiro que recobrem as galhas se rompem, liberando uma massa pulverulenta marrom laranja de bolas de esporos. Tais estruturas são dispersas no meio ambiente e recebem esta denominação devido a serem constituídas por várias células unidas, apresentando o conjunto formato esférido. Bolas de esporos subglobosas ovóides ou elipsóides, com algumas delas bastante irregulares, medindo 30-48 x 28-40 $\mu \mathrm{m}$, marrom amareladas ou com pigmentação escura, quase negra, compostas de 1-2 a 15 bolas de esporos firmemente unidas (Prancha $1-\mathrm{E}$ ). Os esporos são formados sobre as hifas dicarióticas, um seguido ao outro, assemelhando-se à formação de clamidosporos. Esporos poliédricos, hemisféricos ou largamente cuneiformes. Às vezes com áreas de contacto achatadas lisa e irregularmente verrugoso. Germinação não observada neste estudo porém, conforme observado nas descrições de Freire e Vánky, germinação por um promicélio septado, desenvolvendo finas hastes $(3,7,8)$.

\section{AGRADECIMENTOS}

Os autores agradecem a Walter Graeber da Biblioteca do Instituto Biológico e, a Giuliana C. Magalhães, Raquel P. Silveira e Fernanda Feliciano, Engenheiras Agrônomas pelo envio de material e informações importantes.

\section{REFERÊNCIAS BIBLIOGRÁFICAS}

1. CORREIA, M.P. Dicionário de plantas úteis do Brasil e exóticas cultivadas. Rio de Janeiro: Imprensa Nacional, 1926. v. 1, p. 39.

2. DURÁN, R. The species of Tecaphora on Compositae in North America. Canadian Journal of Botany. Ontário, v. 60, p. 1512$1522,1982$.

3. FREIRE, F.C.O. Carvão do jambú (Spilanthes oleraceae L.), uma doença nova para a Região Amazônica brasileira. Fitopatologia Brasileira, Brasília, v. 11, p. 543-555, 1986.

4. PIMENTEL, A.A.M.P. Olericultura no trópico úmido: hortaliças na amazônia. São Paulo: Agronômica Ceres, 1985. 322 p.

5. POLTRONIERI, M.C.; MULLER, N.R.M.; POLTRONIERI, L.S. Recomendações para a produção de jambú: cultivar Nazaré. Circular Técnica Embrapa Amazônia Oriental, n. 11, 2000. $13 \mathrm{p}$.

6. ROCQUE, C. Grande enciclopédia da amazônia. Amazônia Editora, 1967. v. 1, p. 75.

7. VÁNKY, K. Illustrated genera of smut fungi. New York: Fischer, 1987. $159 \mathrm{p}$.

8. VÁNKY, K. Taxonomical studies on Ustilaginales XIV. Mycotaxon, Nova York, v. 59, p. 89-113, 1996. 